\section{Rotavirusinfektion nach Impfung von Kindern mit SCID}

Impfungen mit lebenden, aber abgeschwächten Erregern stellen für Kinder mit einem schweren kombinierten Immundefekt (SCID) eine Gefahr dar. Pädiater aus den USA berichten nun über drei Kinder, bei denen schwere symptomatische Rotavirusinfektionen nach der Impfung auftraten.

Simant olange man für SCID keine Therapie hatte und die Kinder über kurz oder lang starben, wurden die Probleme nach Impfungen in Kauf genommen. Seit Etablierung der Stammzelltransplantation ist jedoch eine Therapie bei SCID möglich. Es war nur eine Frage der Zeit, bis in Ländern mit allgemein empfohlener Rotavirusimpfung Probleme bei Kindern mit SCID - die ja zum Zeitpunkt der Impfung noch unerkannt ist - auftauchen.

In ihrem Beitrag beschreiben Patel und Kollegen drei Fälle von Säuglingen, die innerhalb eines Monats nach der ersten oder zweiten Impfung gegen Rotaviren bedrohliche Durchfälle durch das Impf- virus entwickelten. Nur bei einem Kind traten die Probleme bereits nach der ersten Impfung auf. Alle drei Kinder zeigten eine Lymphopenie.

Bei einem Kind bestand ein Adenosindesaminasemangel, bei dem zweiten eine X-chromosomale SCID mit einer Mutation im Interleukin-2-Rezeptor, beim dritten schließlich wurde der SCID verursacht durch eine homozygote Mutation im RAG1-Gen. Die beiden letztgenannten Kinder erhielten jeweils zwei Stammzelltransplantationen, das erste erhält eine Substitutionstherapie mit dem fehlenden Enzym.

Die Autoren konnten zeigen, dass es sich bei dem verursachenden Rotavirus jeweils um das Virus aus dem Impfstoff handelte. Sie vermuten, dass mütterliche Antikörper das auftretende Probleme nach der ersten Impfung noch verhindert hatten.

Kommentar: Die Autoren machen darauf aufmerksam, wie wichtig es ist, die Diagnose SCID zu stellen, bevor die Kinder sehr schwer verlaufende Infektionen entwickeln. Sie verweisen in diesem $\mathrm{Zu}$ sammenhang auf eine Arbeit von Puck [J Allergy Clin Immun 2007; 120: 760] in der ebenso wie in der unten referierten Studie auf die Möglichkeit hingewiesen wird, SCID durch den Nachweis von „T-cell receptor excision circles" (TREC) zu diagnostizieren. Es sei daran erinnert, dass SCID deutlich häufiger ist als die Organoazidurien, die schon jetzt regelmäßig gescreent werden.

Dr. Hartmut Koch

Patel NC et al. Vaccine-aquired rotavirus in infants with severe combined immundeficiency. N Engl J Med 2010; 362: 314-9

\title{
Neonatales Screening auf SCID machbar
}

Eine japanische Gruppe von Wissenschaftlern untersuchte die Durchführbarkeit der Quantifikation von „T-cell receptor excision circle“ (TRECS) für das Screening auf den schweren kombinierten Immundefekt (SCID) bei Neugeborenen. Sie benutzen dabei ebenfalls „Guthrie-Karten“.

D er schwere kombinierte Immundefekt ist eine genetisch bedingte Störung bei dem die T-Zellen fehlen und die adaptive Immunität schwer gestört ist. Vor der Einführung der Stammzelltransplantation starben alle Kinder an schweren Infektionen. Da diese Infektionen auch heute noch die Kinder bedrohen - bevor die Diagnose gestellt ist und eine Therapie eingeleitet werden kann - ist eine frühe Diagnose sinnvoll. Obwohl die Erkrankung durch die Mutation von wenigstens zehn verschiedenen Genen ausgelöst werden kann, ist allen Kindern gemeinsam, dass die T-Zellen fehlen.

Bei funktionierenden T-Zellen werden kleine zirkuläre DNA-Fragmente durch Rearrangements des T-Zell-Rezeptors gebildet. Diese sogenannten TRECs las- sen sich im peripheren Blut nachweisen. Bei Patienten mit SCID sind sie massiv herabgesetzt. Eine japanische Arbeitsgruppe um Mirinishi hat nun eine Untersuchung vorgelegt, in der sie TRECs im Blut mithilfe von „Guthrie-Karten“ bestimmten. Bei 326 gesunden Kindern konnten normale Wert gemessen werden, bei 15 Kindern mit SCID dagegen extrem niedrige. Es gab weder falsch-positive noch falsch-negative Ergebnisse.

Kommentar: Sollte sich dieses Verfahren als praktikabel erweisen, könnte es eine wesentliche Bereicherung des neonatalen Screenings darstellen. Die Häufigkeit von SCID ist in etwa vergleichbar mit der von Galaktosämie, die schon lange Gegenstand des NeugeborenenScreenings ist. Die Kinder könnten be-

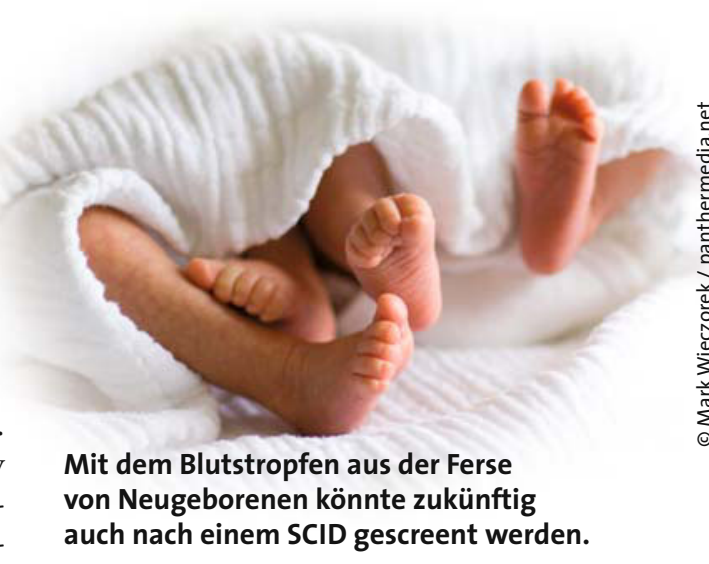

handelt werden, bevor sie an schwer verlaufenden Infektionen erkranken. In derselben Ausgabe der Zeitschrift wird in einer Arbeit von Railey et al. [J Pediatr 2009; 155: 834-40] auf die guten Ergebnisse der Behandlung von SCIDPatienten verwiesen, wenn diese vor einem Alter von dreieinhalb Monaten erfolgt.

Dr. Hartmut Koch

Morinishi Y et al. Identification of severe combined immunodeficiency by T-cell receptor excision circles quantification using neonatal guthrie cards. J Pediatr 2009; 155: 829-33 